How to cite: Chelu, Al., Zaharia, L., Toroimac, I.G. (2020) Temporal and Spatial Variability of Drought Based on SPEI Analysis in Southeastern Romania. 2020 "Air and Water - Components of the Environment" Conference Proceedings, Cluj-Napoca, Romania, p. 71-80, DOI: 10.24193/AWC2020_07.

\title{
TEMPORAL AND SPATIAL VARIABILITY OF DROUGHT BASED ON SPEI ANALYSIS IN SOUTHEASTERN ROMANIA
}

\author{
Alexandra CHELU ${ }^{1,2}$, Liliana ZAHARIA ${ }^{1}$, Gabriela Ioana TOROIMAC ${ }^{1}$
}

DOI: 10.24193/AWC2020_07

\begin{abstract}
This study investigates the drought trends and their spatial variability in southeastern Romania, based on the Standardized Precipitation Evapotranspiration Index (SPEI) analysis (for 1, 3, 6 and 12 months), by using E-OBS precipitation and temperature gridded data between 1950-2018. Trends in the variability of SPEI are analyzed using the Mann-Kendall non-parametric test with the Theil-Sen method for slope estimation. Results show increasing wetness in autumn and dryness during the other seasons for SPEI at 3 months scale, with significant negative trends in winter at the higher altitudes in the study area and in the Danube Delta. SPEI cumulated for 6 months in September shows dryness trends over most of the study area, while SPEI for 6 months in March shows dryness trends only over the western part of the studied region. The results can be useful for designing or improving the regional adaptation practices in order to reduce the negative consequences of droughts in areas affected by drought intensification tendencies.
\end{abstract}

Keywords: drought, SPEI, trends, southeastern Romania, Sen's slope

\section{INTRODUCTION}

Although at global scale the identified drought trends since the 1950's appear to have low confidence (mainly due to issues related to methodology), hotspots of drought change have been observed regionally, such as in the Mediterranean region (IPCC, 2014). In Romania, drought trends have been investigated in several studies whose results showed spatial heterogeneity due to the variability of meteorological variables involved in the occurrence of this phenomenon. One of the most common indices for drought analysis worldwide and in Romania is the Standardized Precipitation Index (SPI) (McKee et al., 1993). Its values showed significant wetness trends in autumn in southeastern Romania, while during winter and spring there are several stations in the Danube Delta region with increasing dryness between 19612010 (Cheval et al., 2014). Between 1962 and 2013, significant decreasing trends in SPI at 3, 6 and 12 months scale in the Danube Delta, and increasing trends in the southeast of Romania (south of Dobrogea region) have been found by Ioniță et al.

\footnotetext{
${ }^{1}$ University of Bucharest (mariaalexandra.chelu@gmail.com)

${ }^{2}$ University of Rennes 2
} 
(2016). These trends follow the distribution of annual precipitation trends (Marin et al., 2014). Bojariu et al. (2015) identified downward trends between $1961-2010$ in SPI cumulated for 6 months, during the hot season (mainly in April to July) especially in the southwest and west parts of the country, as well as in the Danube Delta. Ioniță et al. (2015) have identified, based on the SPI calculated for 6 months between 1901-2013, that drought variability is mostly explained by large scale atmospheric patterns and has observed correlations between increased percentage area affected by drought and positive Arctic Oscillation phases in the Danube catchment, with lead times of 3 months.

In the last years, a widely used index for drought analysis is the Standardized Precipitation Evapotranspiration Index (SPEI), introduced by Vicente-Serrano et al. (2010). Unlike SPI, SPEI takes into account two climatic parameters in determining drought: precipitation and potential evapotranspiration (PET), capturing the main impact of increased temperatures on water demand. Several studies used the SPEI to analyze drought characteristics at European scale (Naumann et al., 2015; Spinoni et al, 2015, 2017, Stagge et al., 2017; Bachmair et al., 2018; Spinoni et al., 2018, 2019). In Romania, Bojariu et al. (2015) analyzed the SPEI trends (cumulated for 6 months, during the period $1961-2010)$ at national scale and showed downward trends (drought intensification) well highlighted in the extra-Carpathian regions of the south and east of the country, especially during spring and summer (March August), with maximum spatial expansion in June - August. The same authors analyzed the spatial trends in the variability of the Palmer Drought Severity Index (PDSI), proposed by Palmer (1965). Their results indicated an aridity tendency between $1961-2010$ mostly in the southwest and southeast of Romania, where in the last 50 years the PDSI has generally increased by more than 2 units.

Based on the analysis of climatic water balance (CWB, calculated as diff erence between precipitation and reference evapotranspiration) dynamics, Prăvălie et al. (2019) showed that Romania has experienced drier conditions in the past half-century (1961-2013) at annual and seasonal time scale (except for autumn). Overall, the negative CWB trends on the analyzed time scales (of up to $-2 \mathrm{~mm} / \mathrm{yr}$ in most cases) have turned extensive regions into drier areas. Statistically, clear drier trends were identified only regionally. Thus, the main hotspots of climatic water deficit amplification are the southwest and southeast, as these regions experienced the highest annual (statistically significant in most cases) and net CWB decreases (Prăvălie et al., 2019).

Croitoru et al. (2013a) investigated the spatio-temporal distribution of aridity indices (De Martonne aridity index and the Pinna combinative index) in the extraCarpathian regions of Romania and found heterogeneous trends of the two indices, most of them statistically insignificant for annual values. At seasonal time scale, statistically significant downward trends (indicating the increasing of the aridity) were found more frequently in winter, while in autumn, aridity appears to decrease over the whole study region, with one third of the trends being statistically significant (most of them in the southeast of the country). 
This study aims to investigate the variability of drought in southeastern Romania, a region that, as shown above, appear to be affected in recent decades by aridity/drought intensification. The interest of this region is related to the fact that it hosts the most developed social-economic areas in Romania, including the capital (Bucharest) and other important cities. At the same time, the lowland part of the study area is one of the most important agricultural areas of the country. Consequently, knowing the spatial and temporal variability of drought in this region has not only scientific, but especially practical interest, for designing or improving the regional and local adaptation measures in order to reduce the negative consequences of droughts. The approach is based on the investigation of the meteorological drought by using the SPEI calculated for 1, 3, 6 and 12-months, based on E-OBS precipitation and temperature gridded data between 1950-2018. This is the first study to use SPEI-1, 3, 6 and 12 at a finer spatial scale ( 0.1 degrees resolution) to explore drought trends over almost a 70-years period in a significant economic region of Romania. Reviewing drought trends by using a longer analysis period is crucial, considering that recent decades have been successively warmer globally.

\section{STUDY AREA, DATA AND METHODS 2.1. Study area}

As already mentioned, the study area corresponds to the southeastern part of Romania (Fig. 1). It extends over $58,476 \mathrm{~km}^{2}$ between $0 \mathrm{~m}$ a.s.1. and about 2,500 $\mathrm{m}$ a.s.l., overlapping on several morphological units: Carpathian Mountains (in the north-western part), Subcarpathian and piedmont hills, and the Romanian Plain. The eastern part of the study region corresponds to the Dobrogea Plateau and Danube Delta, bordered to the east by the Black Sea (Fig. 1). The region is bounded to the south (excepting the south of Dobrogea) and north-east by the Danube River and it is drained by several important direct tributaries of the Danube River, which provide water for social-economic uses (e.g. Argeș, Ialomița). In the Dobrogea Plateau, the hydrographic network is rare and flow is low.

Generally, the region has a temperate continental climate with spatial differentiations imposed by the altitudinal gradient. Because of its geographic position in the eastern part of Romania, the region has excessive continental climatic influence, while the eastern extremity is affected by Pontic influences, induced by the proximity to the Black Sea. The mean multiannual temperature varies from less than $0^{\circ} \mathrm{C}$ on the highest altitudes to $11-12^{\circ} \mathrm{C}$ in the plain area and Dobrogea. The average multiannual amounts of precipitation increase from less than $400 \mathrm{~mm}$ (in southeast) to over $1200 \mathrm{~mm}$ on the Carpathians' heights (NMA, 2008).

The study region has a high importance for agricultural crops (mainly the lowland areas), with more than $68 \%$ of the land used for agriculture, mostly unirrigated, which generates a high vulnerability to drought. Several major cities (county seat) are located in the study area (e.g Pitești, Ploiești, Alexandria, Giurgiu, Călărași, Slobozia, Tulcea, Constanța, Brăila, Galați), including Bucharest, the 
capital of the country and the highest populated city. The high water demands for social-economic needs make the region vulnerable/sensitive to drought.

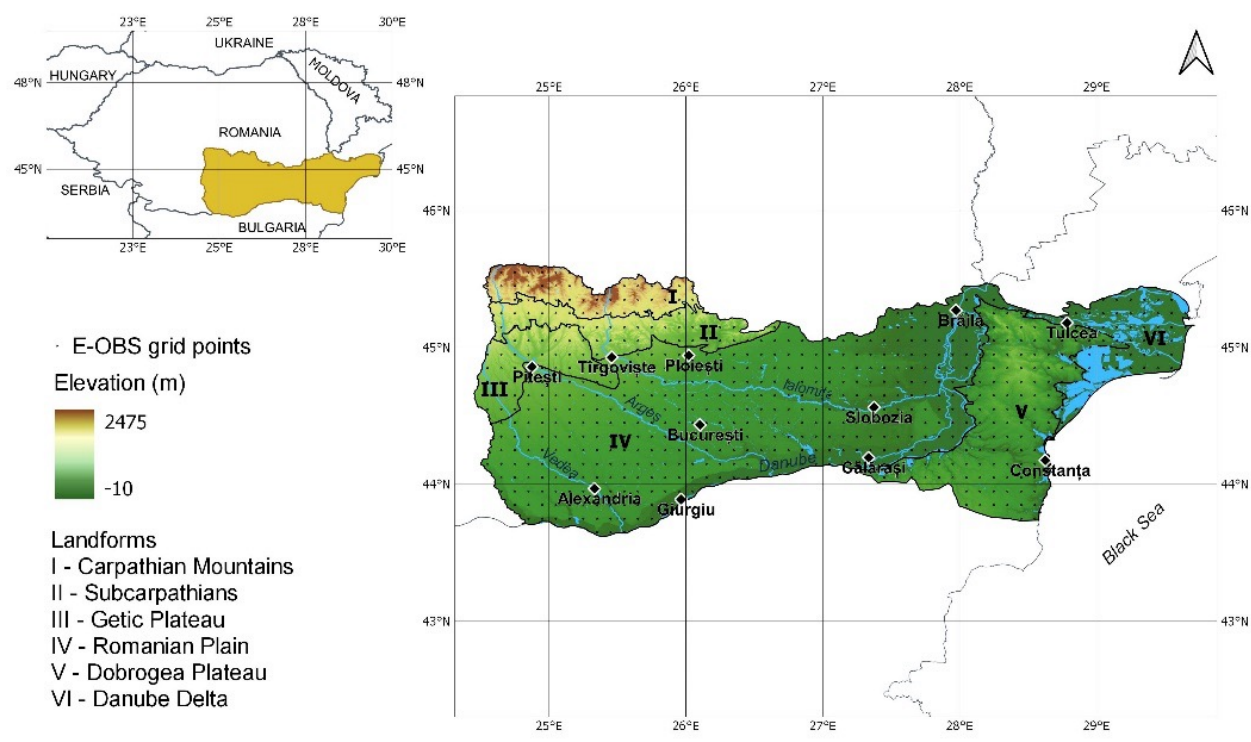

$0 \quad 25 \quad 50 \quad 75 \quad 100 \mathrm{~km}$

Fig. 1. Study area and its location in Romania

\subsection{Data}

The study is based on daily climatic data (precipitation, maximum and minimum temperatures) extracted from the E-OBS gridded dataset $\left(0.1^{\circ} \times 0.1^{\circ}\right.$ grid $)$ for the study area. The time series cover a 69-years period (from 1950 to 2018), for 660 grid points. In this study, the E-OBS v20 ensemble mean dataset was used, interpolated using the ECA\&D stations climatic data (Cornes et al., 2018).

\subsection{Methods}

As mentioned in Introduction, the Standardized Precipitation Evapotranspiration Index (SPEI), introduced by Vicente-Serrano et al. (2010), was used for analyzing the drought variability. The index is based on a simple water balance measure, using the difference between monthly precipitation and reference evapotranspiration (Begueria et al., 2014). This difference between water availability and water demand can be accumulated for different time scale (from 1 to 48 months) to reflect moisture conditions in a particular area. In this study, the SPEI was aggregated at 1, 3, 6 and 12 -months time scale. The Hargreaves method was used to estimate monthly PET using monthly maximum and minimum temperatures. Both evapotranspiration and SPEI were computed using the 'spei' $R$ package. 
Trend detection was performed with the Mann-Kendall test (Mann, 1945, Kendall, 1975) and the slope was estimated with the Theil-Sen estimator (Sen, 1968) for each month time series (12 series for each accumulation scale), using the 'trend' $\mathrm{R}$ package. To estimate trends for the areal average and SPEI-12 series that includes all months, the Trend Free Pre-Whitening Mann-Kendall (TFPW-MK) test by the von Storch (1995) approach was applied using the 'pwmk' R package. A significance level of 0.05 was used to identify significant trends.

\section{RESULTS AND DISCUSSIONS}

Based on the methodology mentioned above, the variability of SPEI was analyzed spatially at different temporal scales. Considering the SPEI for 1, 3, 6 and 12 months averaged over the study area (Fig. 2), we found that there are slight downward trends of SPEI (increasing dryness), however these are not statistically significant. The TFPW-MK test applied on monthly SPEI values for the entire study period (1951-2018) shows generally decreasing SPEI-12 trends across the study area, except the region around Constanța; however, these trends are insignificant.

SPEI-1

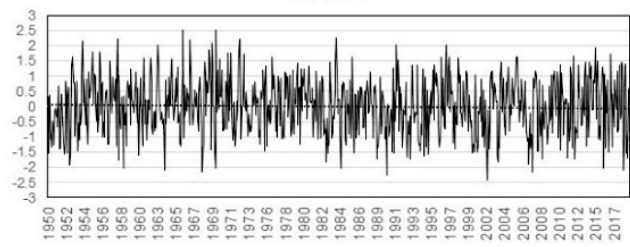

SPEI-6

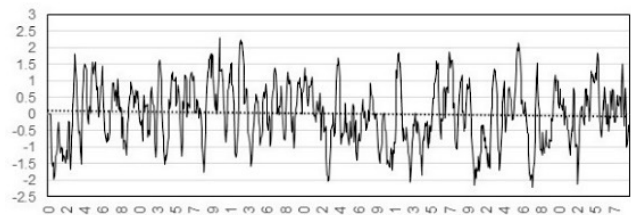

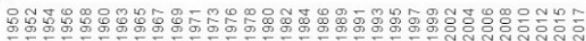

SPEI-3

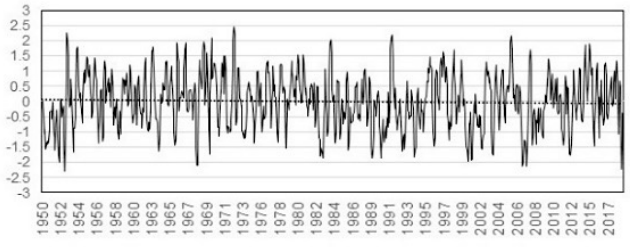

SPEI-12

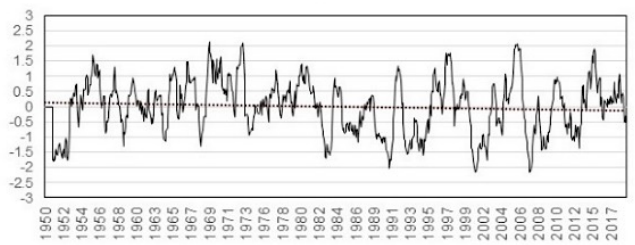

Fig. 2. Variability of the SPEI for 1, 3, 6 and 6 months, averaged over the study area, and their linear trends

The analysis of the spatial variability of trends in SPEI at 1-month time scale (Fig. 3 ) shows that there is a clear trend of increasing wetness in October, statistically significant in the eastern and central parts of the study area. Significant dryness trends have been noticed in the Carpathian and Subcarpathian region in January, February and November, as well as north of Dobrogea in August (Fig. 3).

In

Fig. 4, trends in the variability of SPEI for 3, 6 and 12 months are presented. During the cold season, there are increasing significant dryness trends in the Carpathian and Subcarpathian regions (north-west of the study area), as shown by 
SPEI-3 for winter (including December, January and February) and SPEI-6 for the cold season (considering the period October - March).
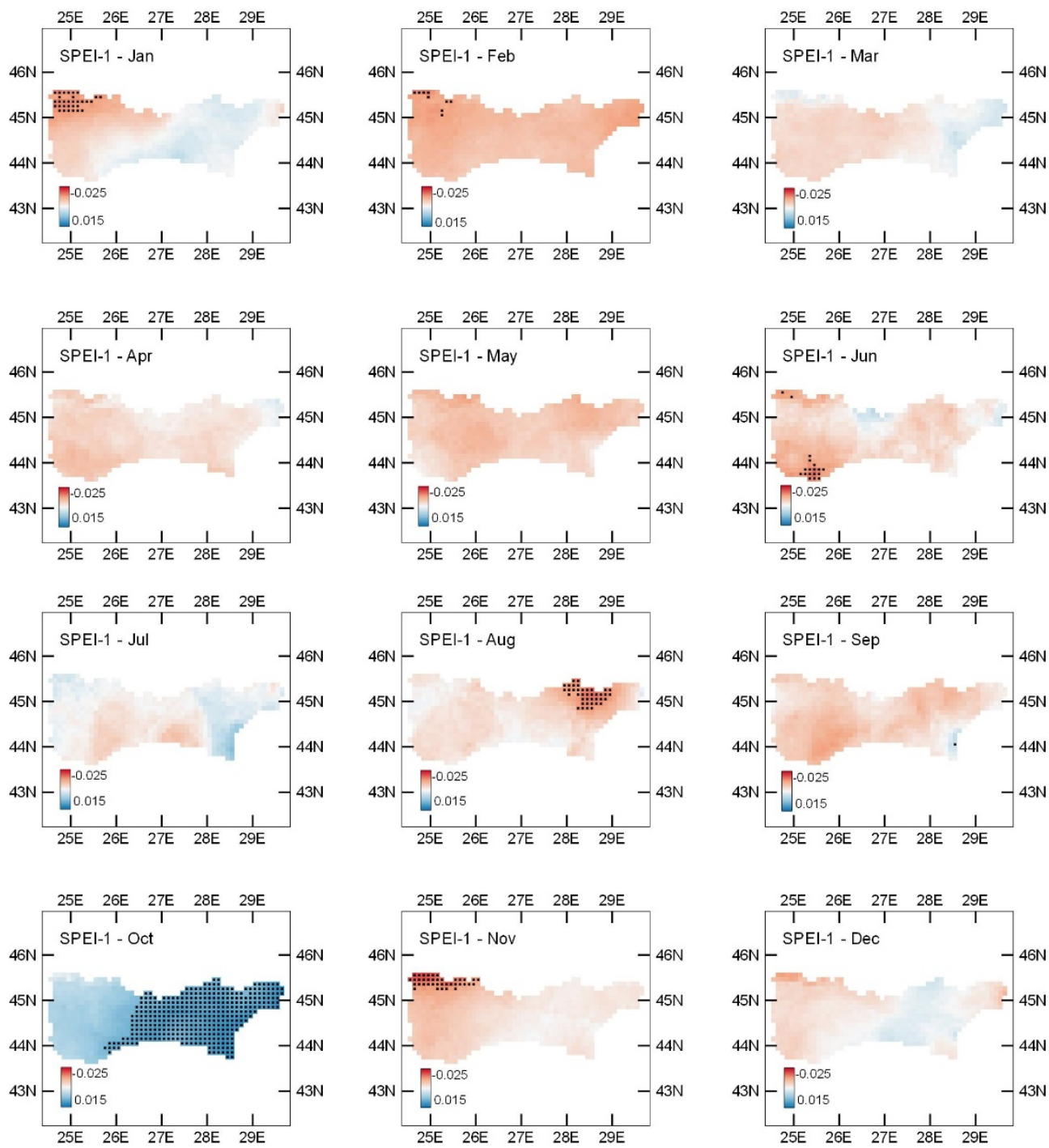

Fig. 3. Spatial variability of Sen's slope in SPEI for 1 month in the study area. Blue shades represent upward trend in SPEI (increasing wetness) and red shades, downward trend (decreasing wetness); black points mark grid points with statistically significant trends

SPEI-3 calculated for autumn (including September, October and November) shows significant increasing trends (wetness) in the southeastern part of the study area, which compared to SPEI-1 for October cover a smaller area. The SPEI-3 trends computed for spring (including March, April and May) are generally negative, except for the eastern extremity. A relatively similar situation was found for the SPEI-3 trends 
during summer (computed for August and including June and July), but the trends intensity is lower (Fig. 4).

Regarding SPEI for 12 months (one-year period January - December), generally there are wetness trends in the southeastern part (South Dobrogea) and dryness trends increasing in magnitude from east to north-west, with significant trends in the mountainous region.
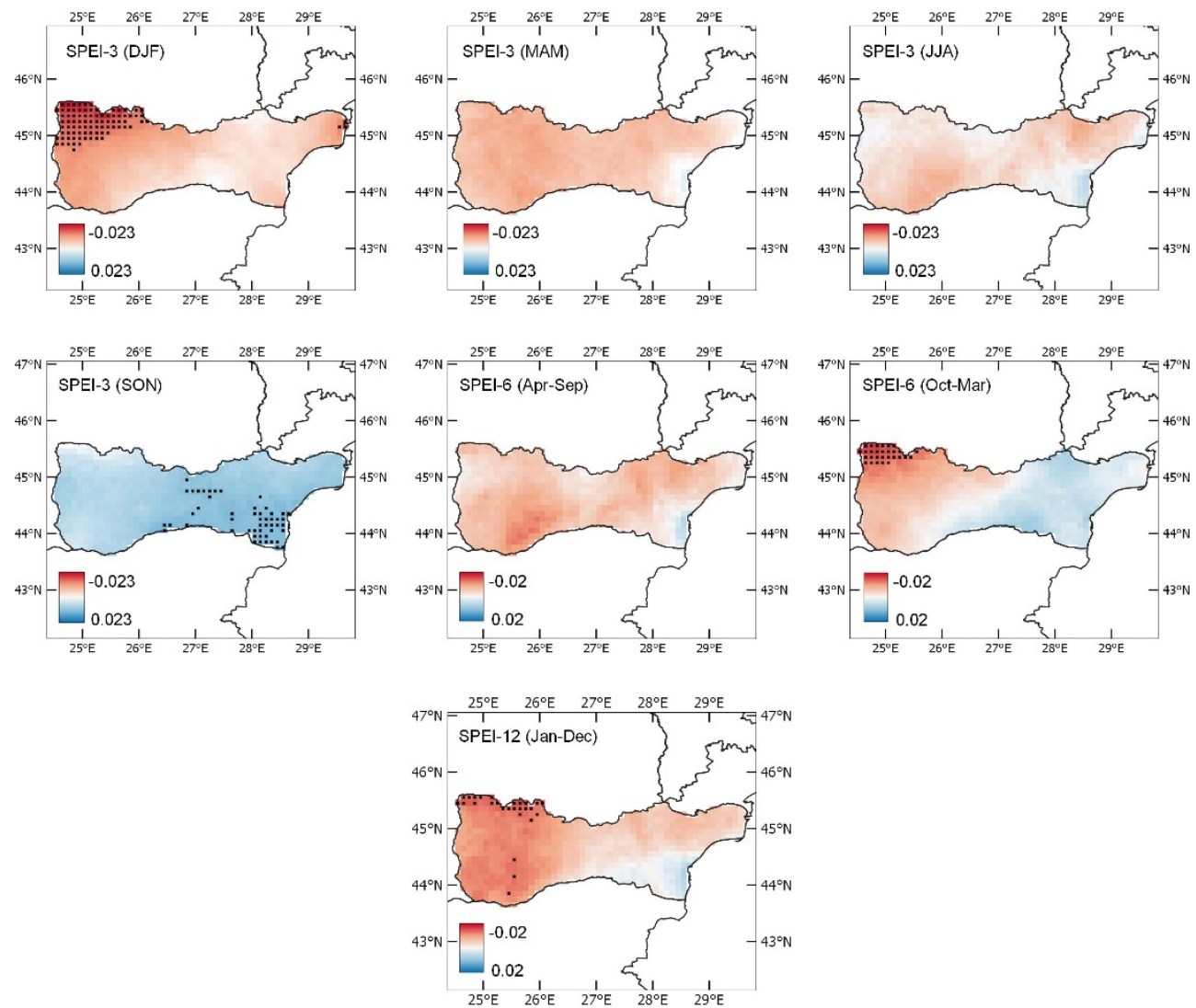

Fig. 4. Spatial variability of Sen's slope in SPEI for 3, 6, 12 months in the study area. Blue shades represent upward trend in SPEI (increasing wetness) and red shades, downward trend (decreasing wetness); black points mark grid points with statistically significant trends

Our results are consistent with those obtained in studies performed at European and national spatial scale. Studies on seasonal trends of SPEI-3 have found decreasing drought frequency in autumn in the study area between 1950-2015 and spatially heterogeneous trends for other seasons, with significant increases in drought event frequency and severity in summer (Spinoni et al., 2017). According to Stagge et al. (2017), drought likelihood increases in southeastern Romania, with higher values over northern Dobrogea region and significant increases over the Danube Delta. The results in Romania have already been synthetized in Introduction. 
Trends in SPEI variability are a consequence of the changes in climatic parameters pertaining to drought. Considering the fact that precipitation does not show significant modifications over most of the study area, the main factor for intensifying aridity is increasing evaporation and evapotranspiration as a consequence of rising air temperatures. Increasing mean annual temperatures have been highlighted (e.g. Marin et al., 2014), while at the seasonal scale there are significant temperature increases during spring and summer (Bojariu et al., 2015; Dumitrescu et al., 2015), which led to the increase of evapotranspiration during these seasons (Croitoru et al., 2013b).

Data from several studies indicate correlations between SPEI at different temporal scales and drought impacts on vegetation and water resources. SPEI accumulated over 1 or 3 months reflect short-term moisture conditions with potential impacts in agriculture due to decreasing soil moisture, while longer accumulation times can reveal effects in river, lakes or groundwater recharge (McKee et al. 1993; Vicente-Serrano et al., 2010). SPEI-12 and SPEI-9 have high correlations with impacts on forestry in the Dobrogea region, while SPEI-3 has high correlations with crop impacts in southeastern Romania (Bachmair et al., 2018). Also, Naumann et al. (2015) have found significant correlations of SPEI-3 severity with crop yields and hydroelectric power production in Romania.

\section{CONCLUSIONS}

In this study, we investigated drought trends by using SPEI at different temporal scales (1, 3, 6 and 12 months) across southeastern Romania, a major economic region with high vulnerability to drought. The study is based on the processing of daily climatic data (precipitation and temperature) extracted from E-OBS gridded database $\left(0.1^{\circ} \times 0.1^{\circ}\right.$ grid $)$ between $1950-2018$. Trends in the variability of SPEI were analyzed by using the Mann-Kendall nonparametric test with the Theil-Sen method for slope estimation.

Considering the SPEI for 1, 3,6 and 12 months averaged over the study area we found that there are slight downward trends of SPEI (increasing dryness), but not statistically significant. Annually, SPEI-12 (in December) indicated wetness trends in the southeastern part (South Dobrogea) and dryness trends increasing in magnitude from east to north-west, with significant trends in the mountainous region. At seasonal time-scale, the SPEI-3 trends showed increasing wetness in autumn (mainly in October) and dryness during the other seasons, with significant negative trends in February in the high-altitude area of the studied region and the Danube Delta. The study could be improved by using a more complex method of calculating reference evapotranspiration, such as the Penman-Monteith, which is recommended by the Food and Agriculture Organization. Our results are consistent with those of previous studies and confirm the general tendency of aridization in most of the region, which requires appropriate adaptation measures to this tendency in order to diminish the negative impacts of drought. 


\section{ACKNOWLEDGEMENTS}

We acknowledge the E-OBS dataset from the EU-FP6 project UERRA (http://www.uerra.eu) and the Copernicus Climate Change Service, and the data providers in the ECA\&D project (https://www.ecad.eu).

\section{REFERENCES}

1. Bachmair, S., Tanguy, M., Hannaford, J., \& Stahl, K. (2018), How well do meteorological indicators represent agricultural and forest drought across Europe? Environmental Research Letters, 13(3). https://doi.org/10.1088/1748-9326/aaafda

2. Beguería, S., Vicente- Serrano, S. M., Reig, F., \& Latorre, B. (2014), Standardized precipitation evapotranspiration index (SPEI) revisited: Parameter fitting, evapotranspiration models, tools, datasets and drought monitoring. International Journal of Climatology, 34(10), 3001-3023. https://doi.org/10.1002/joc.3887

3. Bojariu, R., Bîrsan, M. V., Cică, R., Velea, L., Burcea, S., Dumitrescu, A., ... \& Marin, L. (2015), Schimbările climatice - de la bazele fizice la riscuri şi adaptare. București, Editura Printech.

4. Cheval, S., Busuioc, A., Dumitrescu, A., \& Birsan, M. V. (2014), Spatiotemporal variability of meteorological drought in Romania using the standardized precipitation index (SPI). Climate Research, 60(3), 235-248. https://doi.org/10.3354/cr01245

5. Cornes, R. C., van der Schrier, G., van den Besselaar, E. J. M., \& Jones, P. D. (2018), An Ensemble Version of the E-OBS Temperature and Precipitation Data Sets. Journal of Geophysical Research: Atmospheres, 123(17), 9391-9409. https://doi.org/10.1029/2017JD028200

6. Croitoru, A.-E., Piticar, A., Imbroane, A. M., \& Burada, D. C. (2013a), Spatiotemporal distribution of aridity indices based on temperature and precipitation in the extra-Carpathian regions of Romania. Theoretical and Applied Climatology, 112(3-4), 597-607.

7. Croitoru, A.-E., Piticar, A., Dragota, C. S., \& Burada, D. C. (2013b), Recent changes in reference evapotranspiration in Romania. Global and Planetary Change, 111, 127-136. https://doi.org/10.1016/j.gloplacha.2013.09.004

8. Dumitrescu, A., Bojariu, R., Birsan, M. V., Marin, L., \& Manea, A. (2015), Recent climatic changes in Romania from observational data (1961-2013). Theoretical and Applied Climatology, 122(1-2), 111-119. https://doi.org/10.1007/s00704-014-1290-0

9. Ioniţă, M., Scholz, P., \& Chelcea, S. (2015), Spatio-temporal variability of dryness/wetness in the Danube River Basin. Hydrological Processes, 29(20), 44834497. https://doi.org/10.1002/hyp.10514

10. Ioniță, M., Scholz, P., \& Chelcea, S. (2016), Assessment of droughts in Romania using the Standardized Precipitation Index. Natural Hazards, 81(3), 1483-1498.

11. IPCC. (2014), Climate Change 2014: Impacts, Adaptation, and Vulnerability. Part A: Global and Sectoral Aspects. Contribution of Working Group II to the Fifth Assessment Report of the Intergovernmental Panel on Climate Change [Field, C.B., V.R. Barros, D.J. Dokken, K.J. Mach, M.D. Mastrandrea, T.E. Bilir, M. Chatterjee, K.L. Ebi, Y.O. Estrada, R.C. Genova, B. Girma, E.S. Kissel, A.N. Levy, S. MacCracken, P.R. Mastrandrea, and L.L. White (eds.)]. Cambridge University Press, Cambridge, United Kingdom and New York, NY, USA, 1132 pp. 
12. Kendall, M. G. (1975), Rank correlation methods. 4th Edition, Charles Griffin, London.

13. Mann, H. B. (1945), Non-Parametric Test Against Trend. Econometrica, 13(3), 245-259.

14. Marin, L., Birsan, M. V., Bojariu, R., Dumitrescu, A., Micu, D. M., \& Manea, A. (2014), An overview of annual climatic changes in Romania: Trends in air temperature, precipitation, sunshine hours, cloud cover, relative humidity and wind speed during the 1961-2013 period. Carpathian Journal of Earth and Environmental Sciences, 9(4), 253-258.

15. McKee, T. B., Doesken, N. J., \& Kleist, J. (1993), The relationship of drought frequency and duration to time scales. In Proceedings of the 8th Conference on Applied Climatology (pp. 179-184).

16. Naumann, G., Spinoni, J., Vogt, J. V., \& Barbosa, P. (2015), Assessment of drought damages and their uncertainties in Europe. Environmental Research Letters, 10(12). https://doi.org/10.1088/1748-9326/10/12/124013

17. NMA. (2008), Clima României (Editura Academiei Române). București.

18. Palmer, W. C. (1965), Meteorological Drought. Weather Bureau Research Paper No. 45, U.S. Department of Commerce.

19. Prăvălie, R., Piticar, A., Roșca, B., Sfî̀că, L., Bandoc, G., Tiscovschi, A., \& Patriche, C. (2019), Spatio-temporal changes of the climatic water balance in Romania as a response to precipitation and reference evapotranspiration trends during 1961-2013. Catena, 172, 295-312. https://doi.org/10.1016/j.catena.2018.08.028

20. Sen, P. K. (1968), Estimates of the Regression Coefficient Based on Kendall's Tau. Journal of the American Statistical Association, 63(324), 1379-1389. https://doi.org/10.1080/01621459.1968.10480934

21. Spinoni, J., Naumann, G., Vogt, J., \& Barbosa, P. (2015), European drought climatologies and trends based on a multi-indicator approach. Global and Planetary Change, 127, 50-57. https://doi.org/10.1016/j.gloplacha.2015.01.012

22. Spinoni, J., Naumann, G., \& Vogt, J. V. (2017), Pan-European seasonal trends and recent changes of drought frequency and severity. Global and Planetary Change, 148, 113-130. https://doi.org/10.1016/j.gloplacha.2016.11.013

23. Spinoni, J., Vogt, J. V., Naumann, G., Barbosa, P., \& Dosio, A. (2018), Will drought events become more frequent and severe in Europe? International Journal of Climatology, 38(4), 1718-1736. https://doi.org/10.1002/joc.5291

24. Spinoni, J., Barbosa, P., De Jager, A., McCormick, N., Naumann, G., Vogt, J. V., ... Mazzeschi, M. (2019), A new global database of meteorological drought events from 1951 to 2016. Journal of Hydrology: Regional Studies, 22(January), 100593. https://doi.org/10.1016/j.ejrh.2019.100593

25. Stagge, J. H., Kingston, D. G., Tallaksen, L. M., \& Hannah, D. M. (2017), Observed drought indices show increasing divergence across Europe. Scientific Reports, 7. https://doi.org/10.1038/s41598-017-14283-2

26. Vicente-Serrano, S. M., Beguería, S., \& López-Moreno, J. I. (2010), a multiscalar drought index sensitive to global warming: The Standardized Precipitation Evapotranspiration Index. Journal of Climate, 23(7), 1696-1718. https://doi.org/10.1175/2009JCLI2909.1

27. von Storch, H. (1995), Misuses of statistical analysis in climate research. In Analysis of Climate Variability: Applications of Statistical Techniques. Springer-Verlag: Berlin, 11-26 